\title{
Missed diagnosis and overtreatment of COPD among smoking primary care population in Central Greece: old problems persist
}

This article was published in the following Dove Press journal: International Journal of COPD

\section{Eirini Stafyla \\ Ourania S Kotsiou \\ Konstantina Deskata \\ Konstantinos I \\ Gourgoulianis}

Department of Respiratory Medicine, School of Medicine, University of Thessaly, Biopolis, Larissa,

Thessaly, Greece
Correspondence: Eirini Stafyla Department of Respiratory Medicine, School of Medicine, University of Thessaly, Biopolis, 41500 Larissa, Greece Tel +3024I3502896

Fax +3024 I350 I563 Email eirinistaf@hotmail.com
Background: The diagnosis of COPD is not always consistent with the Global Initiative for Chronic Obstructive Lung Disease (GOLD) strategy in daily clinical practice, especially in primary care. This study aimed to estimate the overall COPD prevalence and severity, to identify differences between newly and previously diagnosed patients, and to evaluate the potential COPD overtreatment in a smoking population attending a primary care spirometry surveillance program.

Methods: A study was conducted in 10 primary health care centers of Central Greece during a 7-month period. Eligible participants were aged $\geq 40$ years and were either current smokers or exsmokers.

Results: A total of 186 subjects were included ( $68 \%$ males, mean age $62.3 \pm 12.6$ years, mean life-time tobacco exposure 50 pack-years). COPD prevalence was $17.8 \%$, identified to be higher in elderly males. Forty-two percent of the COPD group were newly diagnosed patients, who were of younger age, current smokers, presented with less dyspnea and better health status, and mainly appeared with mild-to-moderate disease. Interestingly, $61.4 \%$ of non-COPD and $85.7 \%$ of newly diagnosed COPD individuals had been using inhaled medication under primary care provider's prescription without ever undergoing spirometry or further evaluation by a pulmonologist; thus, the phenomena of COPD overdiagnosis and missed diagnosis came into the spotlight. Moreover, only $26.3 \%$ of known COPD patients were properly medicated according to GOLD guidelines, while half of them were inappropriately treated with triple inhaled therapy.

Conclusion: We reported a significant prevalence of COPD in smoking population attending this spirometry program. A remarkable proportion of COPD patients were undiagnosed and made case finding worthwhile. Underutilization of spirometry in the diagnosis and management of COPD as well as general practitioners' nonadherence to the GOLD treatment guidelines was confirmed by our data. These findings highlight the need for a major overhaul and culture change in primary care settings of Central Greece.

Keywords: COPD management, GOLD guidelines, treatment, spirometry program, primary care

\section{Introduction}

COPD is a chronic respiratory disorder that currently represents a major public health concern worldwide. ${ }^{1}$ It is a major cause of morbidity and mortality at international level, and it has been identified as the third leading cause of death globally. ${ }^{2,3}$ The hallmark of COPD is the presence of airflow obstruction that is not fully reversible, and spirometry is essential for the definite diagnosis of the disease. ${ }^{4}$

Respiratory symptoms - such as cough, sputum production, and dyspnea - may precede the development of airflow limitation by many years; yet significant airflow 
obstruction may develop without symptoms. ${ }^{5}$ Estimates of global COPD prevalence rates vary widely, most likely because of methodological differences between studies. ${ }^{6}$ The prevalence of spirometry-defined COPD in adults was estimated to be $10 \%$ based on the international Burden of Obstructive Lung Diseases (BOLD) survey. ${ }^{7}$ In Greece, the prevalence of COPD was estimated to range between $3.5 \%$ and $18.4 \% .^{5,8-10}$

Primary care physicians (PCPs) play a crucial role in detecting and managing COPD, since they manage the vast majority of patients in the early stages of the disease. ${ }^{4-6,8,11,12}$ However, the diagnosis of COPD by PCPs is not always consistent to the Global Initiative for Chronic Obstructive Lung Disease (GOLD) guidelines in daily clinical practice, mainly because of underuse of spirometry in primary health care (PHC) settings. ${ }^{5,11,13-18}$ As a result, COPD is a disease that is largely underestimated and underdiagnosed. ${ }^{5,11}$ In the USA and Europe, the rate of underdiagnosis varies greatly with the highest estimates reaching up to $86 \%{ }^{13-15}$ Similarly, in Greece, the percentage of undiagnosed COPD patients in the PHC is really high, ${ }^{5,11,16-18}$ with the study of Spyratos et $\mathrm{al}^{11}$ reporting that $52.6 \%$ of COPD cases are undiagnosed. In contrast, overdiagnosis of the disease, a rather common situation in PHC because, again, of nonuse of spirometry or insufficient training of GPs in the interpretation of pulmonary function tests (PFTs), leads to subsequent unnecessary drug overprescription that increases significantly the already high economic burden of disease ${ }^{11}$ as shown previously. ${ }^{19}$ In particular, $\mathrm{PHC}$ is the gateway to the health system and is expected to resolve up to $85 \%$ of health demands as well as to offer comprehensive care coordinated with the other levels of health care. ${ }^{20}$

The aims of the present study were to estimate the overall prevalence and severity of COPD as well as the fraction of already diagnosed and treated COPD patients in a smoking population attending PHC settings in Central Greece, to identify differences between newly and previously diagnosed COPD patients, and to evaluate potential overtreatment in primary care COPD patients.

\section{Methods}

The study was conducted in 10 randomly selected PHC centers in urban, suburban, and rural areas in Thessaly, Central Greece, during a 7-month period (May 2016-November 2016). All subjects were aged $>40$ years, current smokers or exsmokers, resided near a PHC setting, and were willing to participate in a spirometry surveillance program. Exclusion criteria included no smoking history, a history of lower or upper respiratory infection or antibiotic treatment within the last month, an operative procedure or acute myocardial infarction within last 3 months, and inability to perform spirometry. The potentially eligible participants were selected and screened by PCPs (case-finding program). The study was approved by the Ethics Committee of the University Hospital of Larissa, and all subjects provided written informed consent.

\section{Study design}

A survey questionnaire was completed for each participant. The questionnaire included questions on smoking status, occupational exposure, chronic respiratory symptoms (cough, sputum, wheezing, and dyspnea), history of respiratory infections, comorbidities, and history of inhaled medication received during the last 3 years. Additionally, clinical COPD questionnaire (CCQ), COPD assessment test (CAT), and modified Medical Research Council (mMRC) dyspnea scale were completed by all participants. The CCQ was used to assess health-related quality of life (HRQoL). CAT was used to measure the impact of COPD on a person's life and mMRC dyspnea scale to quantify how shortness of breath causes disability. Smoking status was categorized in the following two terms: 1) former smokers included adults who have smoked at least 100 cigarettes in their lifetime but who had quit smoking for at least 12 months and 2) current smokers included adults who have smoked 100 cigarettes in their lifetime and currently smoke cigarettes every day (daily) or some days (nondaily). Smoking status for all subjects was measured in pack-years of cigarette smoking (pys).

\section{Spirometry procedure}

Spirometry test was performed with a dry spirometer (Spirolab, MIR, Rome, Italy) according to American Thoracic Society (ATS) recommendations. ${ }^{21}$ Calibration checks were performed every morning, before the beginning of the spirometry program. Spirometry testing was performed by physicians who had undergone a special training program. Forced expiratory maneuvers were repeated until three reproducible acceptable tests were obtained and the best. Forced expiratory volume in 1 second $\left(\mathrm{FEV}_{1}\right)$, forced vital capacity (FVC), and $\mathrm{FEV}_{1} / \mathrm{FVC}$ ratio were recorded. An acceptable maneuver was defined as follows: 1) an explosive start (no hesitation or sigmoid curve) with a back-extrapolation volume $<150 \mathrm{~mL}$, 2 ) the maneuver was performed with a maximal inspiration and expiration, 3) no glottis closure or cessation of airflow occurred during the maneuver, 4) no coughs (particularly during the first second), inspirations during the trace or 
evidence of leaks, and 5) the maneuver met the end-oftest criteria (exhaling for $\geq 6$ seconds with $<50 \mathrm{~mL}$ being exhaled in the last 2 seconds). ${ }^{22}$ A bronchodilator reversibility test with $400 \mu \mathrm{g}$ of salbutamol was performed in all patients with obstructive spirometry. Obstructive spirometry was defined as an $\mathrm{FEV}_{1} / \mathrm{FVC}$ of $<0.70$ in accordance with GOLD guidelines. ${ }^{23} \mathrm{~A}$ positive response to bronchodilators was defined as an increase in the $\mathrm{FEV}_{1}$ of $200 \mathrm{~mL}$ and $12 \%$ from the prebronchodilator value (baseline value). ${ }^{24}$

\section{Fractional exhaled nitric oxide (FeNO) measurement}

FeNO concentration in exhaled breath was also measured for all subjects. The FeNO levels were measured using a nitric oxide analyzer (NoBreath; Bedfont Scientific Ltd, Maidstone, UK). The testing standards for FeNO followed the guidelines recommended by the ATS and the European Respiratory Society. ${ }^{25}$

\section{Diagnosis of COPD}

After the completion of the study questionnaire, the measurement of FeNO, and spirometry test, all participants were evaluated by respiratory physicians who established the diagnosis of COPD. The presence of COPD was assessed based on medical history, clinical symptoms, and spirometry results. Classification of COPD was based on the postbronchodilator $\mathrm{FEV}_{1}(\%)$ according to GOLD guidelines (Stage I/mild COPD, $\mathrm{FEV}_{1} \geq 80 \%$; Stage II/moderate COPD, $50 \% \leq \mathrm{FEV}_{1}<80 \%$; Stage III/severe COPD, 30\% $\leq \mathrm{FEV}_{1}<50 \%$; Stage IV/very severe COPD, $\mathrm{FEV}_{1} \leq 30 \%$ or $\mathrm{FEV}_{1}<50 \%$ with respiratory failure) ${ }^{23,26}$ Patients with COPD were also allocated into four groups by GOLD (GOLD Groups A, B, C, and D) according to 2016 and 2017 GOLD guidelines. ${ }^{23,26}$ Additionally, for participants with known COPD, an extra questionnaire regarding COPD and exacerbation history was completed. COPD patients were also asked whether they had previously received a chest $\mathrm{X}$-ray (CXR). In terms of the differentiation between COPD and asthma, asthma diagnosis was based on participants' medical history (presence of symptoms from childhood or adolescence and/or seasonal distribution) and the presence of significant reversibility of airway obstruction on spirometry according to GINA guidelines (improvement in the $\mathrm{FEV}_{1}$ of $>12 \%$ and $200 \mathrm{~mL}$ from the baseline spirometry). ${ }^{27}$ Patients with asthma were included in the analysis as non-COPD patients.

\section{Statistical analyses}

Data were analyzed using the statistical program SPSS 22 (IBM Corporation, Armonk, NY, USA). Quantitative variables were presented as mean with standard deviation (SD), and qualitative variables are presented as frequencies with percentages. Chi-square test was used to explore any associations between qualitative variables. To identify differences between two independent groups when the dependent variable was either ordinal or continuous, unpaired $t$-tests or Mann-Whitney $U$ tests were used for normally and skewed data, respectively. Differences between more than two unrelated groups were tested by one-way analysis of variance (ANOVA). A result was considered statistically significant when the $P$-value was $<0.05$.

\section{Results}

Study flowchart is presented in Figure 1. At baseline, 247 subjects were enrolled and screened, but only 204 subjects fulfilled inclusion criteria. Of the 204 eligible participants, 186 participants performed an acceptable spirometry and were included in the analysis. From the subjects included,

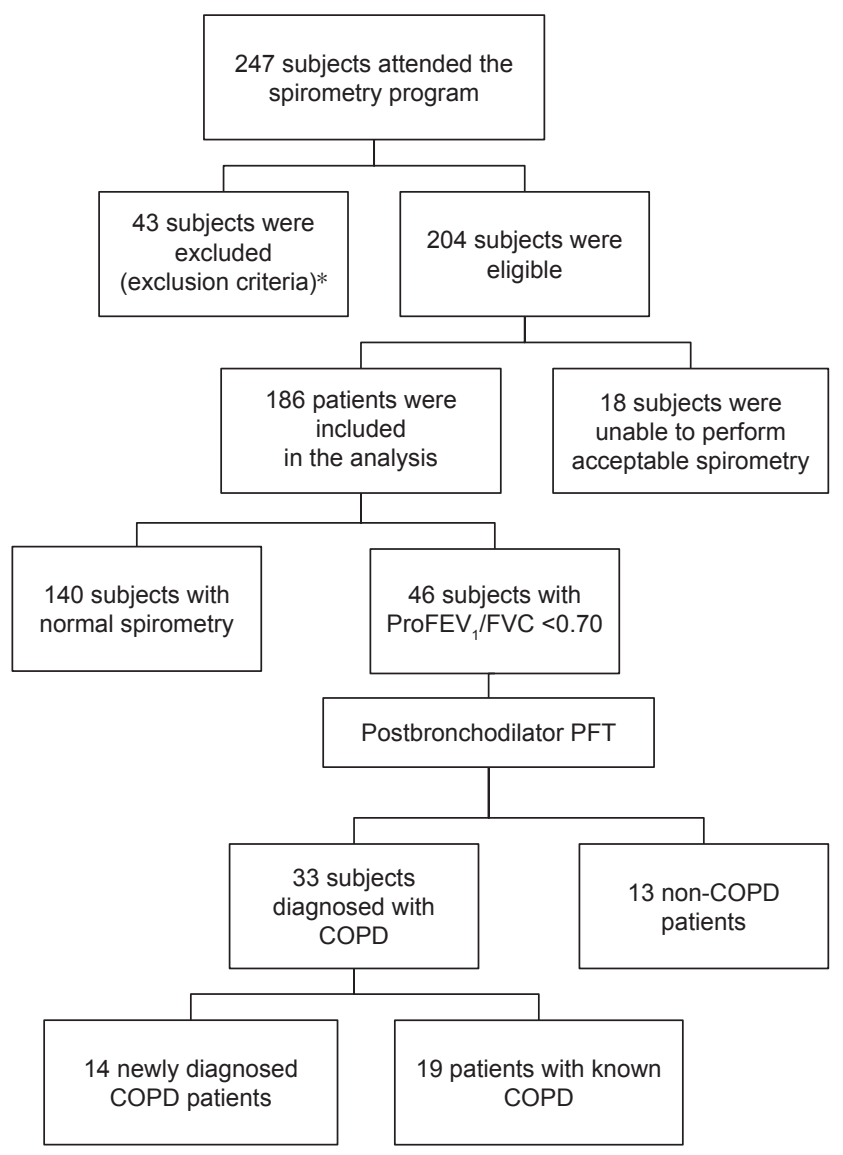

Figure I Flowchart of the study selection process.

Notes: *Exclusion criteria: no smoking history, a history of lower or upper respiratory infection or antibiotic treatment within the last month, an operative procedure or acute myocardial infarction within the last 3 months, or inability to perform spirometry. Excluded subjects: 17 nonsmokers, five subjects aged $<40$ years, II subjects with recent respiratory infection, two subjects with recent operative procedure, and eight subjects who did not cooperate with the spirometry procedure.

Abbreviation: PFT, pulmonary function test. 
46 individuals presented with a prebronchodilator $\mathrm{FEV}_{1} / \mathrm{FVC}$ ratio of $<0.70$. Thirty-three individuals had a postbronchodilator $\mathrm{FEV}_{1} / \mathrm{FVC}$ of $<70 \%$ and diagnosed with COPD. The rest of the 13 subjects were either diagnosed with asthma or in cases with a response that improved postbronchodilator $\mathrm{FEV}_{1} / \mathrm{FVC}>70 \%$ but did not meet the spirometric and/or clinical criteria for asthma diagnosis, referral for further specialized investigations was recommended ${ }^{26}$ (further evaluation of asthma-COPD overlap). This group was included in the analysis as non-COPD patients.

The demographic and clinical characteristics of 186 subjects enrolled into the study are presented in Table 1. Of the 186 subjects, $68.3 \%$ of them were males with a mean age of $62.3 \pm 12.6$ years. At least one comorbid condition was reported in $82 \%$ of the sample, with the most common being arterial hypertension (44.6\%); 82.3\% had at least one respiratory symptom (dyspnea, cough, sputum, and/or wheezing); and $67.2 \%$ of all participants reported that they had been medicated with inhalers for different time periods during the last 3 years, with the combination of LABA/ inhaled corticosteroid (ICS) being the most prescribed treatment $(24.2 \%)$.

Of the 186 subjects, 121 (65.1\%) subjects were current smokers and $65(34.9 \%)$ subjects were exsmokers. The mean estimated life-time tobacco exposure was $59 \pm 48$ pys for exsmokers and $45 \pm 30$ pys for active smokers $(P=0.142)$. A male predominance was detected in both groups $(81.5 \%$ in exsmokers vs $61.2 \%$ in active smokers, $P=0.004$ ). Furthermore, exsmokers were older than active smokers (68.83 \pm 12.44 vs 58.83 \pm 11.26 years, respectively, $P<0.001)$. Exsmokers reported significant dyspnea $(\mathrm{mMRC} \geq 2)$ compared to current smokers (30.8 vs $17.4 \%$, respectively, $P=0.035)$ with no differences in the prevalence of other respiratory symptoms (cough, sputum, and wheezing). Both groups had a high rate of cardiac comorbidities. However, exsmokers had more cardiac comorbidities as compared to active smokers ( 81.5 vs $62 \%$, respectively, $P=0.006$ ), especially suffered from coronary heart disease (75.4 vs $53.7 \%, P=0.007)$ and arterial hypertension (56.9 vs $38 \%$, $P=0.013$ ). Exsmokers had lower proFEV 1 values as compared to current smokers $(2,192 \pm 958$ vs $2,558 \pm 750 \mathrm{~mL}$, $P=0.005)$, as well as lower $\mathrm{FEV}_{1} / \mathrm{FVC}$ ratio $(63.82 \pm 22.89$ vs 78.04 $\pm 18.96, P=0.027)$. No differences were detected in FeNO values $(P=0.228)$ or reversibility $(P=0.743)$ between two groups.

COPD was diagnosed in 33 of the 186 participants providing a COPD prevalence of $17.8 \%$ in the study population. COPD group was constituted of 57.6\% (19/33) exsmokers
Table I Demographic and clinical characteristics of study participants $(\mathrm{N}=186)$

\begin{tabular}{|c|c|}
\hline Characteristics & Total $(n=186)$ \\
\hline Age (years) & $62.3 \pm 12.6$ \\
\hline \multicolumn{2}{|l|}{ Gender } \\
\hline Male & $127(68.3)$ \\
\hline BMI $\left(\mathrm{kg} / \mathrm{m}^{2}\right)$ & $29.1 \pm 5.8$ \\
\hline \multicolumn{2}{|l|}{ Occupational exposure } \\
\hline Yes & $27(\mid 4.5)$ \\
\hline \multicolumn{2}{|l|}{ Area of residence } \\
\hline Urban & $28(15.1)$ \\
\hline Suburban & $59(31.7)$ \\
\hline Rural & $99(53.2)$ \\
\hline \multicolumn{2}{|l|}{ Smoking status } \\
\hline Current smoker & $12 \mid(65.1)$ \\
\hline Exsmoker & $65(34.9)$ \\
\hline Start smoking age (years) & $19.7 \pm 6.9$ \\
\hline Quit smoking age (years) & $53.6 \pm 13.3$ \\
\hline Pack-years of smoking & $50 \pm 37.8$ \\
\hline \multicolumn{2}{|l|}{ Respiratory symptoms } \\
\hline Cough & $92(49.5)$ \\
\hline Sputum & $108(58.1)$ \\
\hline Wheezing & $85(45.7)$ \\
\hline Dyspnea & $105(56.5)$ \\
\hline $\mathrm{mMRC} \geq 2$ & $4 I(22)$ \\
\hline $\mathrm{CAT} \geq 10$ & $57(30.6)$ \\
\hline \multicolumn{2}{|l|}{ Comorbidities } \\
\hline Yes & I $53(82.3)$ \\
\hline Hypertension & $83(44.6)$ \\
\hline Diabetes & $40(21.5)$ \\
\hline Coronary heart disease & $22(11.8)$ \\
\hline Hyperlipidemia & $65(34.9)$ \\
\hline $\mathrm{FeNO}(\mathrm{ppb})$ & $8 \pm 9.2$ \\
\hline ProFEV $\%$ & $86 \pm 21.3$ \\
\hline \multicolumn{2}{|l|}{ Inhaled medication ${ }^{\mathrm{a}}$} \\
\hline No medication & $61(32.8)$ \\
\hline$S A M A \pm S A B A$ & $23(12.3)$ \\
\hline LAMA or LABA & $20(10.7)$ \\
\hline LAMA/LABA & $8(4.3)$ \\
\hline LABA/ICS & $45(24.2)$ \\
\hline LAMA + LABA/ICS & $19(10.2)$ \\
\hline Other medications & $10(5.5)$ \\
\hline
\end{tabular}

Notes: Data are expressed as mean \pm standard deviation or as frequency (percentage). aPreviously received medication.

Abbreviations: BMI, body mass index; CAT, COPD assessment test; FeNO, fractional exhaled nitric oxide; $\mathrm{FEV}_{1}$, forced expiratory volume in I second; ICS, inhaled corticosteroid; mMRC, modified Medical Research Council; LABA, long-acting $\beta 2$-agonist; LAMA, long-acting muscarinic antagonist; SABA, short-acting $\beta 2$-agonist; SAMA, short-acting muscarinic antagonist.

and $42.4 \%(14 / 33)$ active smokers. COPD diagnosis was associated with older age $(71 \pm 10.3$ vs $60.5 \pm 12.3$ years, $P<0.001$ ), male predominance (93.9 vs $62.7 \%, P<0.001$ ), higher CAT (10.5 \pm 7.6 vs $6.7 \pm 6.9, P=0.003)$, and mMRC scores $(P=0.002)$ as well as sputum production $(P=0.008)$. Furthermore, the mean FeNO value was significantly higher in the COPD group compared to that in the non-COPD group (11.68 \pm 13.76 vs $7.25 \pm 7.82 \mathrm{ppb}, P=0.019)$. In Table 2, 
Table 2 Comparisons of COPD and non-COPD groups

\begin{tabular}{|c|c|c|c|}
\hline Characteristics & $\begin{array}{l}\text { Non-COPD } \\
\text { group } \\
(n=I 53)\end{array}$ & $\begin{array}{l}\text { COPD } \\
\text { group } \\
(n=33)\end{array}$ & $P$-value \\
\hline Age (years) & $60.5 \pm 12.3$ & $7 I \pm 10.3$ & $<0.001$ \\
\hline \multicolumn{4}{|l|}{ Gender } \\
\hline Male & $96(62.7)$ & 31 (93.9) & $<0.001$ \\
\hline Occupational exposure & $25(16.3)$ & $2(6.1)$ & 0.128 \\
\hline \multicolumn{4}{|l|}{ Smoking status } \\
\hline Current smoker & $107(69.9)$ & 14 (42.4) & 0.003 \\
\hline Exsmoker & $46(30.1)$ & $19(57.6)$ & 0.003 \\
\hline Start smoking age (years) & $20.1 \pm 7.2$ & $17.9 \pm 5.5$ & $0.069^{a}$ \\
\hline Quit smoking age (years) & $50.6 \pm 11.2$ & $60.8 \pm 15.5$ & 0.003 \\
\hline Pack-years of smoking & $45 \pm 33$ & $75 \pm 48$ & $<0.00 \mathrm{I}^{\mathrm{a}}$ \\
\hline \multicolumn{4}{|l|}{ Respiratory symptoms } \\
\hline Cough & 73 (47.7) & $19(57.6)$ & 0.304 \\
\hline Sputum & $82(53.6)$ & $26(78.8)$ & 0.008 \\
\hline Wheezing & $69(45.1)$ & I 6 (48.5) & 0.723 \\
\hline Dyspnea & $83(54.2)$ & $22(66.7)$ & 0.192 \\
\hline $\mathrm{mMRC} \geq 2$ & $27(17.6)$ & $14(42.4)$ & 0.002 \\
\hline CAT & $6.7 \pm 6.9$ & $10.5 \pm 7.6$ & $0.003^{\mathrm{a}}$ \\
\hline $\mathrm{CAT} \geq 10$ & $43(28)$ & $14(42)$ & 0.106 \\
\hline Total CCQ & $0.91 \pm 0.98$ & $1.68 \pm 1.16$ & $<0.00 I^{\mathrm{a}}$ \\
\hline \multicolumn{4}{|l|}{ Comorbidities } \\
\hline Yes & $94(6 I .4)$ & $26(8 \mid .3)$ & 0.033 \\
\hline Hypertension & $67(43.8)$ & $16(48.5)$ & 0.623 \\
\hline Diabetes & $30(19.6)$ & $10(30.3)$ & 0.175 \\
\hline Coronary heart disease & I7 (II.I) & $5(15.2)$ & 0.514 \\
\hline Hyperlipidemia & 58 (37.9) & $7(2 \mid .2)$ & 0.068 \\
\hline FeNO (ppb) & $7.25 \pm 7.82$ & $11.68 \pm 13.76$ & $0.019^{a}$ \\
\hline \multicolumn{4}{|l|}{ Pulmonary function test } \\
\hline ProFEV,$\%$ & $76.5 \pm 16.6$ & $65.2 \pm 22.5$ & $<0.001$ \\
\hline PostFEV $\%$ & $90 \pm 18.713$ & $68.7 \pm 23.6$ & 0.283 \\
\hline $\begin{array}{l}\text { Reversibility (positive } \\
\text { response) }\end{array}$ & $(8.5)$ & $0(0)$ & 0.083 \\
\hline \multicolumn{4}{|l|}{ Inhaled medication ${ }^{\mathrm{b}}$} \\
\hline Yes & $94(6 \mid .4)$ & 31 (93.9) & 0.001 \\
\hline
\end{tabular}

Notes: Data are expressed as mean \pm SD or as frequencies (percentages). ${ }^{\mathrm{a}}$ MannWhitney $U$ test. 'Previously received medication.

Abbreviations: CAT, COPD assessment test; CCQ, clinical COPD questionnaire; $\mathrm{FeNO}$, fractional exhaled nitric oxide; $\mathrm{FEV}_{1}$, forced expiratory volume in I second; mMRC, modified Medical Research Council; SD, standard deviation.

comparisons of demographic and clinical characteristics of COPD vs non-COPD groups are presented.

Newly diagnosed COPD patients represented $42.4 \%$ of the COPD group. Newly diagnosed patients were younger (66 \pm 10 vs $75 \pm 9$ years, $P=0.009$ ), predominantly current smokers (64.3 vs $35.7 \%, P=0.029)$, presented with lower mMRC scores (mMRC $\geq 2: 21.4$ vs $57.9 \%, P=0.036$ ) compared to the known COPD individuals. Moreover, they had lower total and functional CCQ scores $(P=0.033$ and 0.013 , respectively). One of the five (3/14) newly diagnosed COPD groups included asymptomatic smokers, representing 1.6\% of the study participants. Known COPD patients represented $57.6 \%$ of COPD group (19/33). Comparisons of demographic and clinical characteristics between newly diagnosed and known COPD patients are presented in Table 3.

COPD patients were asked whether they had ever undergone chest imaging by general practitioners (GPs). In known

Table 3 Comparisons of newly diagnosed and known COPD patients

\begin{tabular}{|c|c|c|c|}
\hline Characteristics & $\begin{array}{l}\text { Newly diagnosed } \\
\text { COPD group } \\
(n=14)\end{array}$ & $\begin{array}{l}\text { Known } \\
\text { COPD } \\
\text { group }(n=19)\end{array}$ & $P$-value \\
\hline Age (years) & $65.7 \pm 9.6$ & $74.8 \pm 9.2$ & 0.009 \\
\hline \multicolumn{4}{|l|}{ Gender } \\
\hline Male & $12(85.7)$ & $19(100)$ & 0.089 \\
\hline \multicolumn{4}{|l|}{ Smoking status } \\
\hline Current smoker & $9(64.3)$ & $5(26.3)$ & 0.029 \\
\hline Exsmoker & $5(35.7)$ & $14(73.7)$ & 0.029 \\
\hline $\begin{array}{l}\text { Quit smoking age } \\
\text { (years) }\end{array}$ & $50.5 \pm 13.2$ & $65.2 \pm 14.7$ & 0.049 \\
\hline \multicolumn{4}{|l|}{ Respiratory symptoms } \\
\hline Cough & $8(57.1)$ & II (57.9) & 0.966 \\
\hline Sputum production & $9(64.3)$ & I 7 (89.5) & 0.080 \\
\hline Wheezing & $7(50.0)$ & $9(47.4)$ & 0.881 \\
\hline Dyspnea & $7(50.0)$ & $15(78.9)$ & 0.081 \\
\hline $\mathrm{mMRC} \geq 2$ & $3(2 \mid .4)$ & II (57.9) & 0.036 \\
\hline CAT score & $8 \pm 5.9$ & $12.3 \pm 8.2$ & 0.394 \\
\hline Total CCQ & $1.2 \pm 0.8$ & $2 \pm 1.3$ & 0.033 \\
\hline Symptom CCQ & $1.6 \pm 1$ & $2.1 \pm 1.2$ & 0.204 \\
\hline Mental CCQ & $0.7 \pm 1$ & $1.5 \pm 1.5$ & $0.073^{a}$ \\
\hline Functional CCQ & $1.0 \pm 0.8$ & $2.2 \pm 1.7$ & 0.013 \\
\hline \multicolumn{4}{|l|}{ Vaccination } \\
\hline Influenza & $2(14.3)$ & | 4 (73.7) & 0.001 \\
\hline $\begin{array}{l}\text { Streptococcus } \\
\text { pneumoniae }\end{array}$ & $3(2 \mid .4)$ & $8(42.1)$ & 0.213 \\
\hline $\mathrm{FeNO}(\mathrm{ppb})$ & $7.8 \pm 7.7$ & $13.5 \pm 16.4$ & $0.646^{\mathrm{a}}$ \\
\hline \multicolumn{4}{|l|}{ GOLD classification } \\
\hline Stage I & $5(35.7)$ & $3(15.8)$ & 0.382 \\
\hline Stage II & $7(50)$ & $9(47.4)$ & \\
\hline Stage III & $2(14.3)$ & $6(31.5)$ & \\
\hline Stage IV & 0 & I (5.3) & \\
\hline \multicolumn{4}{|l|}{ GOLD groups 2016} \\
\hline$A$ & $8(57.1)$ & $6(31.6)$ & 0.379 \\
\hline B & $4(28.6)$ & $7(36.8)$ & \\
\hline C & 0 & $2(10.5)$ & \\
\hline $\mathrm{D}$ & $2(14.3)$ & $4(2 I . I)$ & \\
\hline \multicolumn{4}{|l|}{ GOLD groups 2017} \\
\hline$A$ & $8(57.1)$ & $8(42.1)$ & 0.495 \\
\hline B & $5(35.7)$ & $7(36.8)$ & \\
\hline C & 0 & 0 & \\
\hline $\mathrm{D}$ & I (7.I) & $4(2 \mid . I)$ & \\
\hline \multicolumn{4}{|l|}{ Inhaled medication } \\
\hline No medication & $2(14.3)^{b}$ & 0 & 0.083 \\
\hline Only bronchodilators & $7(50.0)^{\mathrm{b}}$ & $6(31.6)$ & \\
\hline Bronchodilators + ICS & $5(35.7)^{b}$ & I $3(68.4)$ & \\
\hline
\end{tabular}

Notes: Data are expressed as mean \pm SD or as frequencies (percentages). aMannWhitney $U$ test. 'Previously received medication.

Abbreviations: CAT, COPD assessment test; $C C Q$, clinical COPD questionnaire; FeNO, fractional exhaled nitric oxide; GOLD, Global Initiative for Chronic Obstructive Lung Disease; ICS, inhaled corticosteroids; mMRC, modified Medical Research Council; SD, standard deviation. 
COPD patients, CXRs were previously performed on $60 \%$ of them, mainly for ruling out alternative diagnoses and comorbid conditions. Regarding newly diagnosed COPD patients, none of them had ever undergone a spirometry and $40 \%$ of them had a CXR previously performed.

Moreover, 93.9\% of all COPD individuals reported that they had received inhaled medication over the last 3 years. Notably, $61 \%$ of healthy individuals and $85.7 \%$ of newly diagnosed patients reported that they had been medicated with inhalers for various time periods under the guidance of GPs. None of them was referred for further diagnostic assessment by a specialist or spirometry testing according to patients' self-reports.

The majority of COPD patients were classified into risk groups A and B. Depending on GOLD system, a rise in the proportion of COPD patients classified in groups $\mathrm{A}$ and $\mathrm{B}$ was observed (from $75.8 \%$ according to 2016 GOLD $^{23}$ classification to $84.8 \%$ according to the latest established classification $^{26}$ ) as presented in Table 3. Furthermore, 85.7\% of newly diagnosed patients were in the mild-to-moderate stage of disease and were classified into Stages I and II. Similarly, we observed an increasing proportion of earlystage newly diagnosed COPD patients when they were reclassified according to 2017 GOLD system (from $85.7 \%$ to $92.8 \%$ according to old and new GOLD guidelines, ${ }^{23,26}$ respectively) (Table 3 ). Moreover, differences in treatment compliance according to GOLD group were observed. Specifically, we found that only $47.4 \%$ of known COPD patients received proper medication according to 2016 GOLD guidelines ${ }^{23}$ and only $26.3 \%$ of known COPD patients received proper medication according to latest treatment guidelines. ${ }^{26}$ Overall, $68.4 \%$ of known COPD patients were medicated with ICSs and approximately half of them were being inappropriately treated with triple inhaled therapy (Table 3 ).

To this end, Table 4 summarizes demographics and clinical characteristics of all COPD patients according to different GOLD stages (I-IV) and different GOLD groups (A-D). We found that COPD patients in GOLD Stage III/IV had significantly higher total CCQ score than early-stage patients, as expected. Finally, taking into account GOLD grouping according to $2016^{23}$ and $2017^{26}$ GOLD definition, we found that Groups B and D had more dyspnea and higher mMRC, CAT, and total CCQ scores compared to Groups A and C, as also expected (Table 4). It is worth mentioning that none of the subjects was allocated to 2017 GOLD Group C. This is in accordance to 2017 GOLD update, ${ }^{26}$ which reported that Group $\mathrm{C}$ is consistently the least prevalent group.

Table 4 Demographics and clinical characteristics of all COPD patients according to different GOLD stages (I-IV) and different 2017 GOLD COPD groups (A-D)

\begin{tabular}{|c|c|c|c|c|c|c|}
\hline \multirow[t]{2}{*}{ Characteristics } & \multicolumn{3}{|c|}{ GOLD stages } & \multicolumn{3}{|c|}{2017 GOLD groups ${ }^{b}$} \\
\hline & $\begin{array}{l}\text { Stage I } \\
(n=8)\end{array}$ & $\begin{array}{l}\text { Stage II } \\
(n=16)\end{array}$ & $\begin{array}{l}\text { Stage III/IV } \\
(n=9)\end{array}$ & $\begin{array}{l}\text { Group A } \\
(n=16)\end{array}$ & $\begin{array}{l}\text { Group B } \\
(n=12)\end{array}$ & $\begin{array}{l}\text { Group D } \\
(n=5)\end{array}$ \\
\hline Age (years) & $73.8 \pm 8.2$ & $67.4 \pm 11.3$ & $74.8 \pm 8.8$ & $70.4 \pm 12.6$ & $70.9 \pm 6.3$ & $72.8 \pm 11.9$ \\
\hline \multicolumn{7}{|l|}{ Gender } \\
\hline Male & 7 (87.5) & $15(93.8)$ & $9(100)$ & $16(100)$ & II (9I.7) & $4(80)$ \\
\hline \multicolumn{7}{|l|}{ Smoking status } \\
\hline Current smoker & $5(62.5)$ & $6(37.5)$ & $3(33.3)$ & $7(43.8)$ & $5(4 \mid .7)$ & $2(40)$ \\
\hline Exsmoker & $3(37.5)$ & $10(62.5)$ & $6(66.6)$ & $9(56.2)$ & $7(58.3)$ & $3(60)$ \\
\hline Quit smoking age (years) & $64 \pm 9.2$ & $56.5 \pm 18$ & $67.2 \pm 11.7$ & $57.4 \pm 13.6$ & $62.4 \pm 16.2$ & $65.5 \pm 21$ \\
\hline Pack-years of smoking & $80 \pm 42.4$ & $62.3 \pm 42.9$ & $92.2 \pm 58.1$ & $79.4 \pm 48.2$ & $75 \pm 53$ & $59 \pm 36.5$ \\
\hline \multicolumn{7}{|l|}{ Respiratory symptoms } \\
\hline Cough & $6(75)$ & $8(50)$ & $5(55.5)$ & $9(56.2)$ & $8(66.7)$ & $2(40)$ \\
\hline Sputum production & $6(75)$ & $12(75)$ & $8(88.8)$ & $12(75)$ & $10(83.3)$ & $4(80)$ \\
\hline Wheezing & $2(25)$ & $9(56.2)$ & $5(55.5)$ & $7(43.8)$ & $6(50)$ & $3(60)$ \\
\hline Dyspnea & $4(50)$ & $10(62.5)$ & $8(88.8)$ & $7(43.8)$ & $10(83.3)^{*}$ & $5(100)^{*}$ \\
\hline $\mathrm{mMRC} \geq 2$ & $4(50)$ & $5(3 \mid .2)$ & $5(55.5)$ & 0 & $9(75)^{* * *}$ & $5(100)^{* *}$ \\
\hline CAT score & 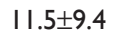 & $8.1 \pm 6.4$ & $13.9 \pm 6.9$ & $4.9 \pm 3.2$ & $15.1 \pm 7.4 * *$ & $17.2 \pm 5.1 * *$ \\
\hline Total CCQ & $1.6 \pm 1.5$ & $1.2 \pm 0.8$ & $2.5 \pm I^{*}$ & $0.9 \pm 0.7$ & $2.2 \pm 1.2 * *$ & $2.8 \pm 0.8 * *$ \\
\hline $\mathrm{FeNO}(\mathrm{ppb})$ & $9.9 \pm 9$ & $11.9 \pm 17.1$ & $|3 \pm| \mid .8$ & $9.4 \pm 7.6$ & $14.8 \pm 20.4$ & $11.6 \pm 11.5$ \\
\hline Newly diagnosed & $5(62.5)$ & $7(43.8)$ & $2(22.2)$ & $8(50)$ & $5(4 I .7)$ & I (20) \\
\hline
\end{tabular}

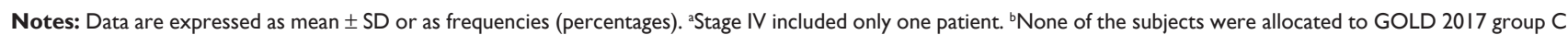
and reported to be consistently the least prevalent group according to 2017 GOLD update. *A statistically significant difference with a $P$-value of $<0.05$. $* * A$ statistically significant difference with a $P$-value of $<0.001$.

Abbreviations: CAT, COPD assessment test; CCQ, clinical COPD questionnaire; FeNO, fractional exhaled nitric oxide; GOLD, Global Initiative for Chronic Obstructive Lung Disease; mMRC, modified Medical Research Council; SD, standard deviation. 


\section{Discussion}

The prevalence of COPD among smokers aged 40 years or older, attending this surveillance program, was $17.8 \%$. Only one-half of COPD patients had already been diagnosed and treated; thus, underdiagnosis and missed diagnosis of COPD patients are a concern. We found that newly diagnosed COPD patients were of younger age, current smokers, and less symptomatic; the majority appeared to have COPD of mild and moderate airflow limitation. Remarkably, gaps seem to exist in the implementation of evidence-based guidelines for managing COPD in PHC. First, the phenomenon of COPD overdiagnosis followed by overtreatment came into spotlight, since $61.4 \%$ of non-COPD subjects were probably misdiagnosed with COPD and medicated without ever performing spirometry to confirm the diagnosis. Furthermore, a great proportion of newly diagnosed COPD patients $(85.7 \%)$ had been using inhaled medication under PCPs' prescription without ever undergoing spirometry. Finally, more convincingly, we found that only $26.3 \%$ of previously known COPD patients were properly medicated according to 2017 GOLD treatment guidelines, while half of them were inappropriately treated with triple inhaled therapy.

Generally, smoking population participated in this PHC spirometry surveillance program viewed mainly the profile of a male current smoker. The male predominance may be explained by the low smoking habit of females in Greece, ${ }^{9,28}$ especially in rural and suburban areas. ${ }^{5}$ Gender-related differences do also exist in COPD patients in Greece. A study conducted in Thessaly (Central Greece) reported that females comprised only $12.5 \%$ of COPD patients. ${ }^{5}$

In addition, in this study, different clinical profile was detected among current smokers and exsmokers. Current smokers were younger than exsmokers, which is consistent to published data. ${ }^{29,30}$ However, quitters had higher mean estimated life-time tobacco exposure and reported significantly more dyspnea ( $\mathrm{mMRC} \geq 2)$ and cardiac comorbidities, especially coronary heart disease and arterial hypertension, compared to active smokers. There is abundant evidence that respiratory effects and health sequences associated with cigarette smoke increase motivation to quit smoking. ${ }^{31}$ Furthermore, it has previously been described that smokingassociated symptoms such as sputum production and dyspnea might not be completely reversible. ${ }^{32}$

Notably, approximately two-thirds (67.2\%) of all study participants reported that they had been treated with inhaled medication over the last 3 years - especially LABA/ICS combination - without ever undergoing PFTs or further evaluation by a pulmonologist. Spyratos et al ${ }^{11}$ consistently documented that GPs prescribe drugs based on patients' symptoms, clinical examination, and smoking history without using spirometry for the confirmation of the respiratory disease. Without COPD determination and proper classification, GPs blindly treat an obstructive pulmonary disease, usually by the prescription of LABA/ICS, in order to "cover" all COPD stages or bronchial asthma. ${ }^{11}$ Moreover, our findings are in agreement with those observed in another Greek study, reporting that LABA/ICS combination was the most frequent medication prescribed, followed by LAMA. ${ }^{33}$

Further analysis of various types of drugs used showed that approximately half of the study participants were medicated with inhalers, while the prevalence of COPD in this particular population was $17.8 \%$. Hence, we can speculate that patients may be too often misdiagnosed with COPD and then overtreated. However, we were not able to reliably verify the accuracy of participants' self-reported diagnoses. It is worth mentioning in this context that $55.4 \%$ of the current costs for COPD medication were found to be wasted to overdiagnosis and overtreatment in Greece. ${ }^{11}$

In this article, we reported a significant proportion of COPD patients being diagnosed by the implementation of a PHC-based spirometry program. The reported COPD prevalence rate of our study was obviously limited by a small sample size; however, it is comparable to that found in previously published larger studies. ${ }^{5,9,11}$ In detail, Spyratos et $\mathrm{al}^{11}$ reported a COPD prevalence of $10.7 \%$ in $\mathrm{PHC}$, and Minas et $\mathrm{al}^{5}$ found a prevalence of $18.4 \%$ in PHC settings of Thessaly (Central Greece) - in a study conducted before the Greek crisis onset (from January 2006 to June 2007), and included 15 PHC centers in Central Greece. Similarly, in the study of Tzanakis et al, ${ }^{9}$ COPD prevalence was recorded to be $15.1 \%$ in males living in rural areas.

Specifically, we found a remarkable proportion of newly diagnosed patients, yet COPD remains grossly undiagnosed in PHC by GPs. The large proportion of undiagnosed COPD cases in a PHC is a silent scourge. ${ }^{4,5,11,16}$ Herein, however, the rate of newly diagnosed COPD cases observed was lower than previously reported at PHC level, even though only highrisk smokers were screened. Specifically, two-fifths (42.4\%) of COPD patients were classified as newly diagnosed, in comparison with two other studies ${ }^{8,11}$ that reported higher proportions of newly diagnosed COPD patients $(69 \%$ and $52.6 \%$, respectively). ${ }^{8,11}$ Crucially, in support of our strategy, offering spirometry to subjects with tobacco/occupational exposure and at least one respiratory symptom was found to be a very effective screening strategy as more than one-third of participants with airway obstruction could be detected. . $^{34,35}$ 
Other studies indicated that in those with risk factors such as $>20$ pack-years of smoking, the diagnostic yield for COPD is relatively high and spirometry should be considered as a method of early case finding. ${ }^{35,36}$ Screening in high-risk smoking groups is also supported by GOLD 2017 guidelines. ${ }^{26}$

Regarding further evaluation of known COPD, we found that CXR is a diagnostic tool for GP, which is mostly used in cases of established COPD. Generally, it has been reported that GPs tend to perform more CXRs than PFTs. Nonetheless, according to established guidelines, CXR is only valuable in excluding alternative diagnoses or identifying significant comorbidities, ${ }^{26}$ as it is usually abnormal in patients with severe COPD but may not show changes in up to one-half of patients with mild and moderate COPD. ${ }^{37,38}$

We documented high proportions of undiagnosed patients with COPD in the early stages of the disease, which is in accordance with previous studies. ${ }^{39-41}$ Moreover, in our study, we found that newly diagnosed COPD patients were of younger age, current smokers, and presented with fewer symptoms. These findings are consistent with previously published data too. ${ }^{5}$

Although current clinical practice guidelines recommend against screening for COPD in asymptomatic individuals, ${ }^{23,42,43}$ there are several studies that have revealed a high prevalence of COPD among smokers with minimal or no symptoms. ${ }^{44}$ In our study, the group of asymptomatic smokers with COPD represented $1.6 \%$ of the study participants and $21 \%$ of those who had COPD. These findings are in accordance with a previous study ${ }^{37}$ showing that the prevalence of COPD in asymptomatic smokers has been $1.5 \%$ when considering the whole group of smokers and $7 \%$ when considering the group of nonsymptomatic smokers. ${ }^{44}$

It is well established that COPD is most prevalent in older adults and males with more comorbidities which is also in accordance with our results. ${ }^{24,45-49}$ A previous study from our group found that $87.7 \%$ of COPD patients report at least one comorbid condition. ${ }^{19}$ FeNO levels in COPD are conflictual, but it seems that smoking habits and disease severity are the most important factors influencing FeNO levels in COPD patients. ${ }^{50,51}$ However, we found no significant difference in FeNO levels between ex- and current smokers or between COPD and non-COPD individuals in contradiction to previous studies. ${ }^{50,51}$

Finally, differences in treatment compliance according to stage of COPD were observed according to 2016 GOLD guidelines, ${ }^{23}$ a phenomenon was emphasized more taking into account the most recently published GOLD guidelines. ${ }^{26}$
In other words, COPD patients in GOLD Grades A and B were frequently overtreated according to both versions of GOLD guidelines. Analogous results were obtained by Papala et $\mathrm{al}^{52}$ who identified an overtreatment in all GOLD grades. Spyratos et al ${ }^{11}$ also previously reported that only $45 \%$ of the subjects were treated according to GOLD guidelines in PHC and 53.1\% of the cases were overtreated. As far as corticosteroid use is concerned, we found that approximately half of the known COPD patients were inappropriately treated with triple inhaled therapy. ICS use in early stages of disease was also documented in the study of Tzovaras et al. ${ }^{53}$

Achieving the optimal management of COPD in PHC is a major challenge. Taken together, our findings strongly suggest that GPs usually prescribe treatment without the use of spirometry and/or without taking into account the severity of airway obstruction. The limited access to spirometry in PHC in Greece remains strongly evident. ${ }^{5}$ Other causes of COPD misdiagnosis are as follows: ${ }^{54} 1$ ) due to the threshold of 0.70 used for defining COPD, leading to underdiagnosis in younger patients and overdiagnosis in older patients; ${ }^{54}$ 2) errors made in PHC due to GP's lack of awareness of COPD; ${ }^{54-59} 3$ ) errors linked to the spirometry test such as technological errors ; $^{54,59-61} 4$ ) differential diagnoses, which causes diagnostic confusion; and finally 5) patient-related factors such as the absence of obvious respiratory symptoms. ${ }^{54,62}$ Given the underdiagnosis and no refreshment in PHC, both highlighted by our study, in combination with the absence of obvious respiratory symptoms, COPD is often established at a late stage. Thus, symptomatic patients may be referred to a specialist only in severe cases, which is associated with increased COPD disease burden, comorbidities, and costs. Interestingly, it has been reported that opportunities to diagnose COPD earlier are missed for $85 \%$ of patients during the 5-year period preceding actual diagnosis. ${ }^{63}$ To facilitate implementation of the guidelines, several actions are needed, such as additional resources, further training for professionals, and improved organizational structure for interprofessional collaboration and patient education. ${ }^{64}$

Regarding limited resources, the medical supply shortages reflect the unfolding humanitarian crisis of the country. ${ }^{65}$ A study conducted at the beginning of economic recession revealed major shortages in rural PHC equipment as only $4.6 \%$ of rural doctors had spirometers available for clinical use. ${ }^{66}$ Consequently, the treatment begins without formal assessment of lung function; the diagnosis is therefore unconfirmed. In fact, spirometry changed the physician's clinical impressions and treatments for approximately one-third of 
cases. ${ }^{20,67-69}$ Another major point is that Greece presents high variability in the distribution of pulmonologists, and therefore, significantly different rates may be observed among regions independently of population risk factors. ${ }^{70}$ Many PHCs are located in the remote areas where access to specialists is limited. Patients living in these areas are usually of old age, and transportation is difficult for them; thus, GPs depend on their experience to diagnose COPD. ${ }^{65,70}$

Moreover, in PHC settings of Greece, there is a lack of training and feedback for diagnostic spirometry by GPs, and both constitute major barriers to its use. ${ }^{11}$ Despite numerous guidelines for COPD management, studies conducted both in Greece and globally have consistently shown underutilization of spirometry in COPD diagnosis ${ }^{71-75}$ and deviations from optimal pharmacological treatment. In other words, gaps exist in the implementation and uptake of evidence-based guidelines for managing COPD in PHC. ${ }^{76}$ Providing a theorydriven and evidenced-based COPD intervention is a research and a clinical practice priority. Raising awareness of COPD among PCPs requires a two-pronged approach: education and empowerment. ${ }^{77}$ Effective forms of continuing medical education (CME) and questionnaires about the treatment and diagnosis guidelines are important tools to improve guideline adherence and implementation. ${ }^{78}$

Additionally, PCPs play a central role in the multidisciplinary team involved in the diagnosis and treatment of patients with COPD. They play a key role to persuade community members to seek medical care from specialists alerting them to the risk factors and symptoms that they should recognize, in order to seek medical attention at an earlier stage in the disease process. ${ }^{77-79}$ Better valuing of preventative medicine will help increase the motivation and effectiveness of PHC. Screening and case-finding strategies as well as validated questionnaires in identified $\operatorname{cases}^{80}$ are the tools in achieving the goal of early diagnosis in COPD. ${ }^{26}$

Access to care and continuity of care are essential for improved quality and greater treatment efficiency to be achieved, ${ }^{81}$ however, their implementation in the context of management of major diseases, such as COPD, diabetes mellitus, and coronary heart disease, is a matter of continual scholarly debate. Barriers to health care access emerged as one of the main negative consequences of austerity in Greece, as the proportion of Greek adults who reported unmet health care needs more than doubled in just 5 years, with $12.2 \%$ of the respondents citing cost as the main reason for not receiving proper treatment or diagnostic tests. ${ }^{82-84}$

Our study presents several limitations. First, the research was limited by a small sample size. Even though we aimed to have a larger sample size, the actual response rate was much lower. The use of a larger sample would improve future studies. Second, a significant limitation of our study lies in the subject selection based on the population attending PHCs. Current smokers and subjects with respiratory symptoms were more likely to attend PHC. Moreover, the enrolled subjects were selected mainly by local GPs; therefore, younger and/or asymptomatic smokers were not easily recruited for the study. These limitations may have influenced the reported prevalence of COPD in our population. Moreover, we aimed mainly at smokers of rural and suburban areas. This may further account for the higher number of male participants, since they represent the vast proportion of smokers in rural and suburban areas of Greece. Therefore, these limitations limit the generalizability of our findings to the general Greek population.

\section{Conclusion}

Our study reported a significant prevalence of COPD in 10 PHC settings in Central Greece and emphasized the crucial role of presymptomatic control in PHC. A remarkable proportion of COPD patients were undiagnosed and made case finding worthwhile. The phenomenon of missed diagnosis and overtreatment in certain individuals also came into spotlight. Moreover, appropriate COPD treatment should be a part of current health care agenda. The majority of our findings match perfectly with the global estimations and observations of previous Greek studies, indicating that no refreshment in primary care is a scourge at general practice. Undoubtedly, COPD affects Greeks with significant economic impact, which profoundly deteriorated by persistent errors in COPD management. Higher index of suspicion for the presence of COPD in high-risk smoking groups, wider use of spirometry, and PCPs' CME should be a priority in order to tackle the scourge of COPD in primary care.

\section{Acknowledgments}

The authors wish to thank the following respiratory physicians for their active participation in the spirometry program: Zoe Daniil, Irini Gerogianni, Theodora Kerenidi, Eleni Karetsi, Andreas Dimoulis, Ilias Karametos, Foteini Malli, Aggeliki Psatha, Foteini Bardaka, Layla Sicha, Charalabos Varsamas, Stylianos Boutlas, and Spyridon Ladias. The authors especially thank the following PCPs for their cooperation and the identification of high-risk individuals: Iliana Kerani, Dimitrios Kanatas, Vasileios Xamos, Vasileios Delezos, Violeta Roka, Maria Papala, Vasileios Gizlis, Fani Sarigianni, and Ioannis Antonopoulos. 


\section{Author contributions}

$\mathrm{ES}$, OSK, KD, and KIG were involved in the acquisition of data and drafting of the manuscript. OSK especially participated in drafting the article and revising it critically for important intellectual content. All authors read and approved the final manuscript. This article has not been presented or published elsewhere.

\section{Disclosure}

The authors report no conflicts of interest in this work.

\section{References}

1. Dal Negro RW, Tognella S, Tosatto R, Dionisi M, Turco P, Donner CF. Costs of chronic obstructive pulmonary disease (COPD) in Italy: the SIRIO study (social impact of respiratory integrated outcomes). Respir Med. 2008;102(1):92-101.

2. Dal Negro RW, Bonadiman L, Turco P, Tognella S, Iannazzo S. Costs of illness analysis in Italian patients with chronic obstructive pulmonary disease (COPD): an update. Clinicoecon Outcomes Res. 2015;7:153-159.

3. Lozano R, Naghavi M, Foreman K, et al. Global and regional mortality from 235 causes of death for 20 age groups in 1990 and 2010: a systematic analysis for the Global Burden of Disease Study 2010. Lancet. 2012;380(9859):2095-2128.

4. Konstantikaki V, Kostikas K, Minas M, et al. Comparison of a network of primary care physicians and an open spirometry programme for COPD diagnosis. Respir Med. 2011;105(2):274-281.

5. Minas M, Hatzoglou C, Karetsi E, et al. COPD prevalence and the differences between newly and previously diagnosed COPD patients in a spirometry program. Prim Care Respir J. 2010;19(4):363-370.

6. Welte T, Vogelmeier C, Papi A. COPD: early diagnosis and treatment to slow disease progression. Int J Clin Pract. 2015;69(3):336-349.

7. Buist AS, Vollmer WM, McBurnie MA. Worldwide burden of COPD in high- and low-income countries. Part I. The burden of obstructive lung disease (BOLD) initiative. Int J Tuberc Lung Dis. 2008;12(7): 703-708.

8. Minas M, Koukosias N, Zintzaras E, Kostikas K, Gourgoulianis KI. Prevalence of chronic diseases and morbidity in primary health care in central Greece: an epidemiological study. BMC Health Serv Res. 2010;10:252.

9. Tzanakis N, Anagnostopoulou U, Filaditaki V, Christaki P, Siafakas N. Prevalence of COPD in Greece. Chest. 2004;125(3):892-900.

10. Sichletidis L, Tsiotsios I, Gavriilidis A, et al. Prevalence of chronic obstructive pulmonary disease and rhinitis in northern Greece. Respiration. 2005;72(3):270-277.

11. Spyratos D, Chloros D, Michalopoulou D, Sichletidis L. Estimating the extent and economic impact of under and overdiagnosis of chronic obstructive pulmonary disease in primary care. Chron Respir Dis. 2016;13(3): 240-246.

12. Spyratos D, Chloros D, Sichletidis L. Diagnosis of chronic obstructive pulmonary disease in the primary care setting. Hippokratia. 2012;16(1): 17-22.

13. Peña VS, Miravitlles M, Gabriel R, et al. Geographic variations in prevalence and under diagnosis of COPD: results of the IBERPOC multicentre epidemiological study. Chest. 2000;118(4):981-989.

14. Rudolf M. The reality of drug use in COPD: the European perspective. Chest. 2000;117(2 Suppl):29S-32S.

15. Stang P, Lydick E, Silberman C, Kempel A, Keating ET. The prevalence of COPD: using smoking rates to estimate disease frequency in the general population. Chest. 2000;117(5 Suppl 2):354S-359S.

16. Kotrogianni F, Malli F, Gourgoulianis KI. Underdiagnosis of respiratory diseases during an economic downturn and the need for spirometry as a screening test. J Bras Pneumol. 2013;39(2):254-255.
17. Alexopoulos EC, Malli F, Mitsiki E, Bania EG, Varounis C, Gourgoulianis KI. Frequency and risk factors of COPD exacerbations and hospitalizations: a nationwide study in Greece (Greek Obstructive Lung Disease Epidemiology and health ecoNomics: GOLDEN study). Int J Chron Obstruct Pulmon Dis. 2015;10:2665-2674.

18. Minas M, Verrou-Katsarou I, Mystridou P, Apostolidou E, Hatzoglou C, Gourgoulianis KI. Two-year mortality of patients with COPD in primary health care: an observational study. Int J Gen Med. 2012;5: $815-822$.

19. Stafyla E, Kerenidi T, Gerogianni I, Geitona M, Daniil Z, Gourgoulianis KI. The pharmacological cost of COPD during Greek economic crisis. Int J Chron Obstruct Pulmon Dis. 2017;12:461-466.

20. Partridge MR. Enhancing the diagnosis and management of COPD in primary care. Multidiscip Respir Med. 2014;9(1):62.

21. American Thoracic Society. Standardization of spirometry, 1994 update. Am J Respir Crit Care Med. 1995;152(3):1107-1136.

22. Moore VC. Spirometry: step by step. Breathe. 2012;8:232-240.

23. The Global Initiative for Chronic Obstructive Lung Disease (GOLD) [homepage on the Internet]. Global strategy for the diagnosis, management and prevention of chronic obstructive pulmonary disease (updated 2016). Available from: http://www.goldcopd.org/. Accessed May 23, 2017.

24. Global Initiative for Asthma [homepage on the Internet]. Pocket guide of asthma management and prevention. A pocket guide for health professionals - updated 2017. Available from: http://ginasthma.org/. Accessed May 23, 2017.

25. American Thoracic Society; European Respiratory Society. ATS/ ERS recommendations for standardized procedures for the online and offline measurement of exhaled lower respiratory nitric oxide and nasal nitric oxide, 2005. Am J Respir Crit Care Med. 2005;171(8): 912-930.

26. The Global Initiative for Chronic Obstructive Lung Disease (GOLD) [homepage on the Internet]. Global strategy for the diagnosis, management and prevention of chronic obstructive pulmonary disease (2017 report). Available from: http://www.goldcopd.org/. Accessed July 10, 2017.

27. Karachaliou F, Kostikas K, Pastaka C, Bagiatis V, Gourgoulianis KI. Prevalence of sleep-related symptoms in a primary care population their relation to asthma and COPD. Prim Care Resp J. 2007;16(4): 222-228.

28. Papaioannou AI, Bania E, Alexopoulos EC, Mitsiki E, Malli F, Gourgoulianis KI. Sex discrepancies in COPD patients and burden of the disease in females: a nationwide study in Greece (greek obstructive lung disease epidemiology and health ecoNomics: GOLDEN study). Int J Chron Obstruct Pulmon Dis. 2014;9:203-213.

29. Nozawa D, Franken RA, Ribeiro Kde C, Pereira AC, Sprovieri SR, Golin V. Comparative study of smokers, ex-smokers, and nonsmokers who have experienced myocardial infarction. Arq Bras Cardiol. 2003; 81(6):589-591.

30. Sahger D, Cercek B, Cannon CP, et al. How do smokers differ from non smokers in their response to trombolisis (The TIMI-4 trial). Am J Cardiol. 1995;75:232-236.

31. Caponnetto P, Polosa R. Common predictors of smoking cessation in clinical practice. Respir Med. 2008;102(8):1182-1192.

32. Rush D. Changes in respiratory symptoms related to smoking in a teenage population: the results of two linked surveys separated by one year. Int J Epidemiol. 1976;5(2):173-178.

33. Souliotis K, Kani C, Papageorgiou M, Lionis D, Gourgoulianis K. Using big data to assess prescribing patterns in greece: the case of chronic obstructive pulmonary disease. PLoS One. 2016;11(5):e0154960.

34. Ulrik CS, Løkke A, Dahl R, et al. TOP study group: early detection of COPD in general practice. Int J Chron Obstruct Pulmon Dis. 2011;6: $123-127$.

35. Hill K, Goldstein RS, Guyatt GH, et al. Prevalence and underdiagnosis of chronic obstructive pulmonary disease among patients at risk in primary care. CMAJ. 2010;182(7):673-678. 
36. López Varela MV, Montes de Oca M, Rey A, et al; PUMA Team. Development of a simple screening tool for opportunistic COPD case finding in primary care in Latin America: the PUMA study. Respirology. 2016;21(7):1227-1234.

37. Muller NL, Coxson H. Chronic obstructive pulmonary disease. 4: imaging the lungs in patients with chronic obstructive pulmonary disease. Thorax. 2002;57:982-985.

38. Dewar M, Curry RW. Chronic obstructive pulmonary disease: diagnostic considerations. Am Fam Physician. 2006;73(4):669-676.

39. Vandevoorde J, Verbanck S, Gijssels L, et al. Early detection of COPD a case finding study in general practice. Respir Med. 2007;101(3): 525-530.

40. Bednarek M, Maciejewski J, Wozniak M, Kuca P, Zielinski J. Prevalence, severity and underdiagnosis of COPD in the primary care setting. Thorax. 2008;63:402-407.

41. Llordés M, Jaén A, Almagro P, et al. Prevalence, risk factors and diagnostic accuracy of COPD among smokers in primary care. COPD 2015;12(4):404-412.

42. Guirguis-Blake JM, Senger CA, Webber EM, Mularski RA, Whitlock EP Screening for chronic obstructive pulmonary disease: evidence report and systematic review for the US Preventive Services Task Force. JAMA. 2016;315(13):1378-1393.

43. Qaseem A, Wilt TJ, Weinberger SE, et al; American College of Physicians; American College of Chest Physicians; American Thoracic Society; European Respiratory Society. Diagnosis and management of stable chronic obstructive pulmonary disease: a clinical practice guideline update from the American College of Physicians, American College of Chest Physicians, American Thoracic Society, and European Respiratory Society. Ann Intern Med. 2011;155(3):179-191.

44. Sansores RH, Velázquez-Uncal M, Pérez-Bautista OL, Villalba-Caloca J, Falfán-Valencia R, Ramírez-Venegas AL. Prevalence of chronic obstructive pulmonary disease in asymptomatic smokers. Intern $J$ COPD. 2015;2015(10):2357-2363.

45. WaatevikM, Skorge TD, Omenaas E, BakkePS, Gulsvik A, Johannessen A. Increased prevalence of chronic obstructive pulmonary disease in a general population. Respir Med. 2013;107(7):1037-1045.

46. Sharifi H, Masjedi MR, Emami H, et al. Interim report from burden of obstructive lung disease (BOLD Study) in Tehran: prevalence and risk factors of chronic obstructive pulmonary disease. Tanaffos. 2014;13(3):6-13.

47. Halldin CN, Doney BC, Hnizdo E. Changes in prevalence of chronic obstructive pulmonary disease and asthma in the US population and associated risk factors. Chron Respir Dis. 2015;12(1):47-60.

48. Landis SH, Muellerova H, Mannino DM, et al. Continuing to confront COPD international patient survey: methods, COPD prevalence, and disease burden in 2012-2013. Int J Chron Obstruct Pulmon Dis. 2014; 9:597-611

49. Adeloye D, Basquill C, Papana A, Chan KY, Rudan I, Campbell H. An estimate of the prevalence of COPD in Africa: a systematic analysis. COPD. 2015;12(1):71-81.

50. Sterk PJ, de Gouw HW, Ricciardolo FL, Rabe KF. Exhaled nitric oxide in COPD: glancing through a smoke screen. Thorax. 1999;54(7): 565-567.

51. Malerba M, Radaeli A, Olivini A, et al. Exhaled nitric oxide as a biomarker in COPD and related comorbidities. Biomed Res Int. 2014; 2014:271918.

52. Papala M, Kerenidi N, Gourgoulianis KI. Everyday clinical practice and its relationship to 2010 and 2011 GOLD guideline recommendations for the management of COPD. Prim Care Respir J. 2013; 22(3):362-364.

53. Tzovaras NZ, Kouloumenta VN, Gourgoulianis KI. The economic impact of late detection of COPD in general practice. Chest. 2005;127(1): 412-413.

54. Hangaard S, Helle T, Nielsen C, Hejlesen OK. Causes of misdiagnosis of chronic obstructive pulmonary disease: a systematic scoping review. Respir Med. 2017;129:63-84.
55. Akhtar R, Wilson A. A comparison of spirometry in general practice and a pulmonary function laboratory. Prim Care Respir J. 2005;14(4): 215-220.

56. Albers M, Schermer T, Molema J, et al. Do family physicians' records fit guideline diagnosed COPD? Fam Pract. 2009;26(2):81-87.

57. Strong M, Green A, Goyder E, et al. Accuracy of diagnosis and classification of COPD in primary and specialist nurse-led respiratory care in Rotherham, UK: a cross-sectional study. Prim Care Respir J. 2014; 23(1):67-73.

58. Lucas AE, Smeenk FJ, Smeele IJ, van Schayck OP. Diagnostic accuracy of primary care asthma/COPD working hypotheses, a real life study. Respir Med. 2012;106(8):1158-1163.

59. Walters JA, Hansen EC, Johns DP, Blizzard EL, Walters EH, WoodBaker R. A mixed methods study to compare models of spirometry delivery in primary care for patients at risk of COPD. Thorax. 2008; 63(5):408-414.

60. Bolton CE, Ionescu AA, Edwards PH, Faulkner TA, Edwards SM, Shale DJ. Attaining a correct diagnosis of COPD in general practice. Respir Med. 2005;99(4):493-500.

61. Enright PL. Should we keep pushing for a spirometer in every doctor's office? Respir Care. 2012;57(1):146-153.

62. Akamatsu K, Yamagata T, Kida Y, Tanaka H, Ueda H, Ichinose M. Poor sensitivity of symptoms in early detection of COPD. COPD. 2008;5(5): 269-273.

63. van Weel C. Towards earlier diagnosis of COPD. Lancet Respir Med. 2014;2(4):248-249.

64. Lundell S, Tistad M, Rehn B, Wiklund M, Holmner Å, Wadell K. Building COPD care on shaky ground: a mixed methods study from Swedish primary care professional perspective. BMC Health Serv Res. 2017;17(1):467.

65. Rachiotis G, Kourousis C, Kamilaraki M, Symvoulakis EK, Dounias G, Hadjichristodoulou C. Medical supplies shortages and burnout among greek health care workers during economic crisis: a pilot Study. Int $J$ Med Sci. 2014;11(5):442-447.

66. Oikonomidou E, Anastasiou F, Dervas D, et al. Rural primary care in Greece: working under limited resources. Int J Qual Heal Care. 2010; 22(4):333-337.

67. Jose BP, Camargos PA, Cruz Filho AA, Correa Rde A. Diagnostic accuracy of respiratory diseases in primary health units. Rev Assoc Med Bras. 2014;60(6):599-612.

68. Mapel DW, Dalal AA, Johnson P, Becker L, Hunter AG. A clinical study of COPD severity assessment by primary care physicians and their patients as compared to spirometry. Am J Med. 2015;128(6):629-637.

69. Celli BR. Recommendations for the early diagnosis of COPD: the AIMAR view. Multidiscip Respir Med. 2015;10(1):6.

70. Mitsiki E, Bania E, Varounis C, Gourgoulianis KI, Alexopoulos EC. Characteristics of prevalent and new COPD cases in Greece: the GOLDEN study. Int J Chron Obstruct Pulmon Dis. 2015;10: 1371-1382.

71. Davis KJ, Landis SH, Oh YM, et al. Continuing to Confront COPD International Physician Survey: physician knowledge and application of COPD management guidelines in 12 countries. Int J Chron Obstruct Pulmon Dis. 2015;10:39-55.

72. Bourbeau J, Sebaldt RJ, Day A, et al. Practice patterns in the management of chronic obstructive pulmonary disease in primary practice: the CAGE study. Can Respir J. 2008;15:(1)13-19.

73. Glaab T, Vogelmeier C, Hellmann A, Buhl R. Guideline-based survey of outpatient COPD management by pulmonary specialists in Germany. Int J Chron Obstruct Pulmon Dis. 2012;7:101-108.

74. HernandezP, Balter MS, Bourbeau J, Chan CK, Marciniuk DD, Walker SL. Canadian practice assessment in chronic obstructive pulmonary disease: respiratory specialist physician perception versus patient reality. Can Respir J. 2013;20(2):97-105.

75. Price D, West D, Brusselle G, et al. Management of COPD in the UK primary-care setting: an analysis of real-life prescribing patterns. Int J Chron Obstruct Pulmon Dis. 2014;9:889-904 
76. Liang J, Abramson MJ, Zwar $\mathrm{N}$, et al. Interdisciplinary model of care (RADICALS) for early detection and management of chronic obstructive pulmonary disease (COPD) in Australian primary care: study protocol for a cluster randomised controlled trial. BMJ Open. 2017;7(9):e016985.

77. Voelkel NF. Raising awareness of COPD in primary care. Chest. 2000;117(5 Suppl 2):372S-375S.

78. Sandelowsky H, Krakau I, Modin S, Ställberg B, Nager A. Case method in COPD education for primary care physicians: study protocol for a cluster randomised controlled trial. Trials. 2017;18:197.

79. Mulvale G, Embrett M, Razavi SD. "Gearing Up" to improve interprofessional collaboration in primary care: a systematic review and conceptual framework. BMC Fam Pract. 2016;17:83.

80. Spyratos D, Haidich AB, Chloros D, Michalopoulou D, Sichletidis L. Comparison of three screening questionnaires for chronic obstructive pulmonary disease in the primary care. Respiration. 2017;93(2): 83-89.
81. Koponen AM, Simonsen N, Suominen S. Quality of primary health care and autonomous motivation for effective diabetes self-management among patients with type 2 diabetes. Health Psychol Open. 2017; 4(1):2055102917707181.

82. Kyriopoulos II, Zavras D, Skroumpelos A, Mylona K, Athanasakis K, Kyriopoulos J. Barriers in access to healthcare services for chronic patients in times of austerity: an empirical approach in Greece. Int $J$ Equity Healt. 2014;13:54.

83. Zavras D, Zavras AI, Kyriopoulos II, Kyriopoulos J. Economic crisis, austerity and unmet healthcare needs: the case of Greece. BMC Health Serv Res. 2016;16:309.

84. Filippidis FT, Gerovasili V, Millett C, Tountas Y. Medium-term impact of the economic crisis on mortality, health-related behaviours and access to healthcare in Greece. Sci Rep. 2017;7:46423.

\section{Publish your work in this journal}

The International Journal of COPD is an international, peer-reviewed journal of therapeutics and pharmacology focusing on concise rapid reporting of clinical studies and reviews in COPD. Special focus is given to the pathophysiological processes underlying the disease, intervention programs, patient focused education, and self management protocols.

\section{Dovepress}

This journal is indexed on PubMed Central, MedLine and CAS. The manuscript management system is completely online and includes a very quick and fair peer-review system, which is all easy to use. Visit http://www.dovepress.com/testimonials.php to read real quotes from published authors.

Submit your manuscript here: http://www.dovepress.com/international-journal-of-chronic-obstructive-pulmonary-disease-journal 